Available online at: https://jurnal.unej.ac.id/index.php/JLC
LEARNING COMMUNITY
Jurnal Pendidikan Luar Sekolah, $4(1), 2020,20-22$

\title{
Keberdayaan Perempuan Melalui Pelatihan Pengolahan Sampah Pada Kelompok PKK Kelurahan Sumbersari Jember
}

\author{
Puji Dewi Mustika Ningati, Deditiani Tri Indrianti, Muhammad Irfan Hilmi \\ Pendidikan Luar Sekolah, Universitas Jember. Jl. Kalimantan No. 37, Tegal Boto, Jember 62811, Indonesia \\ Email : pujidewi007@gmail.com
}

\begin{abstract}
Abstrak
Penelitian ini bertujuan untuk mengetahui hubungan pelatihan pengolahan sampah terhadap keberdayaan perempuan pada kelompok pemberdayaan kaum perempuan. Jenis penelitian menggunakan penelitian korelasional dengan pendekatan kuantitatif. Hasil penelitian menunjukkan bahwa nilai interpretasi antara pelatihan pengolahan sampah dengan keberdayaan perempuan tergolong memiliki hubungan yang rendah. Nilai rhitung sebesar 0,324 masuk pada kriteria keempat antara 0,200-0,390. Rendahnya hubungan pelatihan dengan keberdayaan perempuan dikarenakan singkatnya jarak pengambilan data keberdayaan perempuan dengan pelatihan pengolahan sampah. Hal demikian berdampak pada data keberdayaan yang diperoleh tidak dapat menunjukkan peningkatan yang signifikan karena diperlukan beberapa jeda waktu dan pendampingan secara berkelanjutan agar keberdayaan perempuan dapat terlihat. Pelatihan pengolahan sampah yang telah dilakukan berdampak positif pada perubahan pola pikir perempuan yang semakin maju yaitu jika perempuan dapat menjadi agen perubahan hanya dengan mengolah sampah menjadi barang bermanfaat dengan nilai jual yang tinggi.
\end{abstract}

Kata Kunci: keberdayaan perempuan, pelatihan, pengolahan sampah

\section{Women's Empowerment Through Waste Management Training on Family Welfare Empowerment Group, Sumbersari Jember}

\begin{abstract}
This study aims to determine the relationship of waste management training to women's empowerment in women's empowerment groups. This type of research uses correlational research with quantitative approaches. The results showed that the value of interpretation between waste management training and women's empowerment was classified as having a low relationship. The calculated value of 0.324 entered the fourth criterion between 0.200-0.390. The low relationship of training with women's empowerment is due to the short distance of data collection on women's empowerment with waste management training. Such an impact on the empowerment data obtained cannot show a significant increase because it requires some time lag and ongoing assistance so that women's empowerment can be seen. The waste management training that has been carried out has a positive impact on changes in the mindset of women who are getting more advanced, that is, if women can become agents of change only by processing waste into useful goods with high selling points.
\end{abstract}

Keywords: women's empowerment, training, waste processing. 


\section{Learning Community: Jurnal Pendidikan Luar Sekolah, 4 (1), Maret 2020 - 21}

Puji Dewi Mustika Ningati

\section{PENDAHULUAN}

Pertumbuhan penduduk kota yang tinggi serta meningkatnya kegiatan pembangunan diberbagai sektor menimbulkan berbagai masalah di wilayahwilayah perkotaan yang salah satunya adalah sampah. Permasalahan sampah timbul karena tidak seimbangnya produksi sampah dengan pengelolaannya.

Pengelolaan sampah juga dapat diartikan sebagai upaya untuk mengolah sampah dengan menggunakan metode atau cara-cara tertentu sesuai dengan jenis sampah Kamal dalam Mistrika (2017:3). Tiga cara yang dapat dilakukan untuk mengolah sampah yang sudah terkumpul meliputi: 1). Reduce yaitu mengurangi segala sesuatu yang menyebabkan timbulnya sampah, 2). Reuse yaitu menggunakan kembali sampah yang masih digunakan baik untuk fungsi yang sama atau fungsi yang lain, dan 3). Recycle yaitu mengolah sampah menjadi produk baru.

Proses pengolahan sampah rumah tangga dapat diberikan melalui proses pelatihan. Menurut Umar dalam Salinding (2011:16), menyatakan bahwa pelatihan bertujuan untuk memperbaiki penguasaan berbagai keterampilan dan teknik pelaksanaan kerja untuk kebutuhan sekarang.

Pelatihan juga bertujuan agar warga belajar pelatihan cepat berkembang, sebab sulit bagi seseorang untuk mengembangkan dirinya hanya berdasarkan pengalaman tanpa adanya suatu pendidikan khusus. Ini membuktikan bahwa pengembangan diri akan lebih cepat melalui pelatihan. Pengolahan sampah menjadi bahan-bahan yang lebih bermanfaat juga dapat membatu dalam upaya memberdayakan masyarakat terutama kaum perempuan melalui berbagai jenis keterampilan, peningkatkan kreativitas, menambah pengetahuan dan dapat berperan dalam pengentasan kemiskinan dan mewujudkan kemandirian ekonomi.

Adapun tujuan dari penelitian yang dilakukan yaitu untuk mengetahui besarnya hubungan antara pelatihan pengolahan sampah dengan keberdayaan perempuan pada kelompok PKK di Kelurahan Sumbersari Kabupaten Jember.

\section{METODE}

Jenis penelitian yang digunakan adalah penelitian korelasional dengan pendekatan kuantitatif. Analisis data yang digunakan adalah korelasi spearman. Lokasi penentuan tempat yaitu dengan metode purposive area. Subyek penelitian yang diambil adalah teknik total sampling yaitu sebesar 39 responden. Waktu yang digunakan dalam penelitian ini adalah 4 bulan. Metode pengumpulan data dilakukan dengankuesioner dan dokumentasi. Pada kuesioner terdiri dari 20 pernyataan, selanjutnyadilakukan proses editing, coding, dan scoring. Apabila keseluruhan item pernyataan tersebut telah terisi, maka dilakukan analisis data lebih lanjut dengan menggunakan rumus spearman yang diolah dengan SPSS 22.

\section{HASIL DAN PEMBAHASAN}

Berdasarkan perhitungan diperoleh rhitung sebesar 0,32. Pada taraf signifikansi $5 \%$ diperoleh nilai sebesar 0,044 yang lebih kecil dari 0,05. Dengan hasil tersebut berarti signifikansi sehingga $\mathrm{Ha}$ diterima dan Ho ditolak. Berdasarkan hasil tersebut maka dapat disimpulkan bahwa ada hubungan antara pelatihan pengolahan sampah dengan keberdayaan perempuan.

Hubungan pelatihan pengolahan sampah dan keberdayaan perempuan berdasarkan hasil analisis peneliti masih tergolong kategori rendah disebabkan karena pelatihan pengolahan sampah yang dilakukan tidak langsung memberikan dampak peningkatan keberdayaan perempuan secara signifikan. Diperlukan beberapa jeda waktu untuk dapat mengetahui peningkatan keberdayaan perempuan dari pelatihan pengolahan yang dilakukan. Namun berdasarkan hasil tabel korelasi diatas telah menunjukkan jika pelatihan pengolahan sampah yang diadakan memberikan pengaruh terhadap keberdayaan perempuan meskipun pengaruhnya masih rendah

Sedangkan pengaruh metode pelatihan dan keberdayaan memiliki nilai korelasi $r$ sebesar 0,380 masuk pada kriteria keempat antara 0,200-0,390. Dengan demikian dapat dikatakan bahwa pelatihan pengolahan sampah memiliki hubungan yang rendah dengan keberdayaan 


\section{Learning Community: Jurnal Pendidikan Luar Sekolah, 4 (1), Maret 2020 - 22}

Puji Dewi Mustika Ningati

perempuan pada kelompok PKK Kelurahan Sumbersari. Berdasarkan analisis peneliti, hubungan antara metode pelatihan dengan keberdayaan perempuan masih tergolong rendah karena beberapa model pelatihan tidak efektif dalam menyampaikan materi kepada peserta pelatihan. Rendahnya hubungan antara metode dan keberdayaan perempuan juga dikarenakan rentang waktu antara pelatihan dan penilaian keberdayaan perempuan yang relative singkat, sehingga dampak dari pelatihan terhadap keberdayaan perempuan masih belum terlihat. Namun, pelatihan yang telah diadakan memberikan pemahaman kepada peserta pelatihan khususnya perempuan memahami dengan sangat baik bagaimana mengolah sampah menjadi barang yang lebih memiliki nilai ekonomis yang nantinya dapat membantu meningkatkan perekonomian keluarga.

Hasil penelitian terhadap pengaruh media pelatihan terhadap keberdayaan perempuan pun juga menunjukkan adanya hubungan antara media dengan keberdayaan perempuan. Meskipun nilai korelasi berada pada tingkat yang rendah, namun keduanya tetap memiliki korelasi. Rendahnya hubungan antara media pelatihan dengan keberdayaan perempuan dikarenakan singkatnya waktu pengambilan data keberdayaan perempuan dengan pelatihan pengolahan sampah. Hal demikian berdampak pada data keberdayaan yang diperoleh tidak dapat menunjukkan peningkatan signifikan karena diperlukan beberapa waktu dan pelatihan secara kontinu agar hubungan antara pelatihan dan keberdayaan dapat terlihat secara signifikan.
Berdasarkan hasil penelitian yang telah diuraikan dapat disimpulkan bahwa Pelatihan pengolahan sampah yang telah dilakukan berdampak positif pada perubahan pola pikir perempuan yang semakin maju yaitu jika perempuan dapat menjadi agen perubahan hanya dengan mengolah sampah menjadi barang bermanfaat dengan nilai jual yang tinggi

\section{DAFTAR PUSTAKA}

Mistrika, S. 2017. Hubungan Pelatihan Mengolah Sampah Dan Pengelolaan Sampah Dengan Keberdayaan Perempuan Kelompok Pemberdayaan Kesejahteraan Keluarga (PKK) Di Dusun Sajen Pacet Mojokerto. Jurnal Pendidikan Luar Sekolah, 1(1):0-158

Salinding, Rony. (2011). Analisis Pengaruh Pelatihan Terhadap Produktivitas Kerja Karyawan Pada PT. Erajaya Swamsebada Cabang Makasar. Skripsi. Makassar: Universitas Hasanuddin Makasar

Sugiyono. 2007. Metode Penelitian Kuantitatif, Kualitatif, dan $R \quad \& \quad D$. Bandung: Alfabeta.

Tato, Syahriar. 2012. Evaluasi Pengelolaan Sampah Kabupaten Gowa Studi Kasus Kecamatan Somba Opu. Universitas 45 Makassar,65-78

Wangi, L., A. $2015 . \quad$ Pemberdayaan Perempuan Melalui Pengelolaan Sampah Di Desa Sidoarjo, Kecamatan Purworejo, Kabupaten Purworejo. Skripsi. Yogyakarta: Universitas Negeri Yogyakarta

\section{SIMPULAN}

